\title{
Impact of a nutrition award scheme on the food and nutrient intakes of 2- to 4-year-olds attending long day care
}

\author{
Lucinda K Bell ${ }^{1}$, Gilly A Hendrie ${ }^{2}$, Jo Hartley ${ }^{3}$ and Rebecca K Golley ${ }^{1, *}$ \\ ${ }^{1}$ Sansom Institute for Health Research (Public Health Group), Division of Health Sciences, University of South \\ Australia, IPC CEA 19, GPO Box 2471, Adelaide, SA 5001, Australia: ${ }^{2}$ Commonwealth Scientific Industrial \\ Research Organisation (CSIRO), Animal, Food and Health Sciences, Adelaide, Australia: ${ }^{3}$ Start Right Eat Right \\ Manager, Southern Primary Health, Start Right-Eat Right, Morphett Vale, Australia
}

Submitted 5 January 2014: Final revision received 5 November 2014: Accepted 28 November 2014: First published online 28 January 2015

\begin{abstract}
Objective: Early childhood settings are promising avenues to intervene to improve children's nutrition. Previous research has shown that a nutrition award scheme, Start Right - Eat Right (SRER), improves long day care centre policies, menus and eating environments. Whether this translates into improvements in children's dietary intake is unknown. The present study aimed to determine whether SRER improves children's food and nutrient intakes.

Design: Pre-post cohort study.

Setting: Twenty long day care centres in metropolitan Adelaide, South Australia, Australia.

Subjects: Children aged 2-4 years ( $n 236$ at baseline, $n 232$ at follow-up).

Methods: Dietary intake (morning tea, lunch, afternoon tea) was assessed pre- and post-SRER implementation using the plate wastage method. Centre nutrition policies, menus and environments were evaluated as measures of intervention fidelity. Comparisons between baseline and follow-up were made using $t$ tests. Results: At follow-up, $80 \%$ of centres were fully compliant with the SRER award criteria, indicating high scheme implementation and adoption. Intake increased for all core food groups (range: $0 \cdot 2-0 \cdot 4$ servings/d, $P<0 \cdot 001$ ) except for vegetable intake. Energy intake increased and improvements in intakes of eleven out of the nineteen nutrients evaluated were observed.

Conclusions: SRER is effective in improving children's food and nutrient intakes at a critical time point when dietary habits and preferences are established and can inform future public health nutrition interventions in this setting.
\end{abstract}

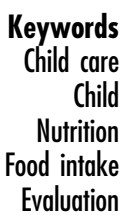

Keywords

Child

Nutrition

Evaluation
Young children increasingly spend a significant proportion of their day in early childhood settings. These settings frequently provide meals and snacks to children while they are in care and offer promising avenues for improving children's nutrition ${ }^{(1,2)}$. For example, long day care centres (LDCC) operate daily for a minimum of $8 \mathrm{~h}$ and often provide more than half of children's daily food intake $^{(3)}$. Therefore it is important that the foods offered to children while in care provide the energy and nutrients they require for optimal growth and development.

In South Australia (SA), Start Right - Eat Right (SRER) is a nutrition award scheme that has been rolled out by government state-wide since 2004. SRER aims to increase LDCC capacity to provide safe, healthy food choices and a positive eating environment for children ${ }^{(4)}$. Participation in SRER involves nutrition training for centre directors and cooks plus support for staff to improve the LDCC menus, policies and eating environment in line with the nutrition award criteria. The SRER award recognises centres that have: (i) a menu that provides at least $50 \%$ of children's daily nutrition requirements; (ii) all staff trained in food hygiene; and (iii) a supportive eating environment for children. An auditing process ensures that once trained and awarded, the SRER criteria are maintained ${ }^{(4,5)}$.

Previous research has shown the positive impact of SRER on the menus, policies and eating environment of LDCC. For example, previously published research reported that $80 \%$ of fifty-one centres made changes to their menus as a result of participating in SRER ${ }^{(5)}$. A 2007 process evaluation study showed an increase in policy criteria met from 8.4 (range: 3-14 out of 18) before SRER participation to $17 \cdot 1$ (range: $13-18$ ) after SRER participation. Staff interviewed in that study also reported changes in staff nutrition and menu development knowledge ${ }^{(4)}$. 
In 2010, we conducted a telephone survey with 184 directors from both SRER-awarded and non-SRER LDCC. We found that LDCC practices were in line with mealtime environment recommendations but were enhanced by involvement in SRER ${ }^{(6)}$. SRER aims to improve children's nutrition and health. However, whether improvements in nutrition policies ${ }^{(4)}$, menus ${ }^{(5)}$ and staff nutrition practices ${ }^{(6)}$ translate into improvements in children's dietary intake is unknown.

International research on the role of early childhood settings to support children's nutrition and health is at a similar stage to that described above for SRER. A 2011 review by Larson and colleagues identified a small number of studies that have assessed the quality of foods provided to and consumed by children in child-care settings ${ }^{(7)}$. However, to date, these evaluations have been crosssectional comparisons of food provision or consumption against policy or regulation frameworks ${ }^{(7)}$. Prospective evaluation of nutrition interventions in early childhood settings have focused primarily on changes in staff knowledge, confidence, attitudes and behaviours, or the nutrition environment ${ }^{(7)}$.

Outcome evaluation that includes assessment of children's dietary intake is needed to assess whether early childhood settings are able to realise their potential as settings to optimise children's dietary intake. Therefore the objective of the present study was to determine the impact of participation in a nutrition award scheme on the food and nutrient intakes of young children while in LDCC.

\section{Methods}

\section{Study design}

The study was a pragmatic pre-post programme evaluation. In 2012 an opportunity arose to evaluate the implementation of SRER in twenty LDCC that were previously ineligible for the SRER award because they were unwilling to change their nutrition policy (J Hartley, personal communication). New ownership of this LDCC chain removed this barrier. However, inclusion of a control group was not possible due to the programme implementation timetable already being established prior to researchers becoming involved in the project. The study was conducted according to the guidelines laid down in the Declaration of Helsinki and all procedures involving human subjects/patients were approved by the University of South Australia Human Research Ethics Committee (UniSA HREC \#26875).

Researchers visited each of the twenty LDCC on two occasions: (i) at baseline, pre-SRER training; and (ii) at follow-up, approximately 2-6 months later, once the LDCC had received nutrition award status indicating they had fully implemented the SRER programme. The primary outcome was children's dietary intake. Intervention fidelity was also assessed including the centres' nutrition policy, menu, food safety training and eating environment.

\section{Recruitment and consent}

The directors of twenty Early Learning LDCC scheduled to participate in SRER training in February or March 2012 were approached, inviting their centre to participate in the study. Children aged 2-4 years who would be present in a single (over two's) room at the LDCC for morning tea, lunch and afternoon tea on the study visit day were eligible for the study. Children with medical conditions limiting their dietary intake were excluded. Parental consent was obtained using an opt-out method.

\section{Intervention description}

Centre directors and cooks received $9 \mathrm{~h}$ of nutrition training from SRER dietitians. The training covered general child nutrition, the importance of children's eating environment, menu modification, and developing and improving a nutrition policy. After the training, centres worked with SRER dietitians to analyse a two-week current menu using an invoice-based menu assessment tool ${ }^{(8)}$. The central office also worked with SRER dietitians to review the nutrition policy that was adopted by all centres. A log book was also collected to indicate that all staff were trained in food hygiene and safety using an in-house video and subsequent quiz. SRER dietitians conducted a centre site visit at a mutually convenient time. During this visit, staff behaviours and practices during mealtimes were observed, and the menu and evidence of nutrition programming in child-care activities sighted using a checklist. This visit was also used to give and receive feedback on the programme implementation and involved the cook, staff and director. SRER dietitians supported each centre by reviewing progress and providing resources and feedback until centres met all SRER award criteria. That is, the menu provided $50 \%$ of a child's daily nutritional requirements, the policy covered important nutrition issues for child-care centres and the eating environment was supportive of healthy eating behaviours ${ }^{(4,5)}$.

\section{Data collection}

\section{Dietary intake}

Children's dietary intake while in care was estimated cross-sectionally at baseline and follow-up using the plate wastage method. At morning tea, lunch and afternoon tea, a dietitian observed and recorded children's food and drink (excluding water) intakes. Each plated serving and leftovers were weighed to the nearest $0 \cdot 1 \mathrm{~g}$ using electronic kitchen scales. Occasionally LDCC staff plated up standard portions for each meal prior to food service and in these cases an average measure was assumed. LDCC staff were briefed on the study and assisted data collection by ensuring leftovers were not discarded prior to weighing. Details of the foods provided, including recipes, types and brands of foods, were obtained from the centre cook. Food intake was calculated as consumption $(\mathrm{g})=$ provided (g) - leftovers (g). 
Grams of food provided and consumed were entered into FoodWorks Professional version 9 (Xyris Software Pty Ltd, Queensland, Australia) and energy and nutrient intakes estimated using Australian food composition data $^{(9)}$. Food, energy and nutrient data were exported from FoodWorks into Microsoft ${ }^{\circledR}$ Access, with the individual eight-digit food item codes, and exported via Microsoft Excel into the statistical software package SPSS Statistics version 17.0. Extremes in weight (grams), energy and nutrient intakes were checked and the plausibility of food and beverage quantities assessed.

Foods were categorised into food group servings per day (grains, vegetables, fruit, dairy, meat and alternatives, fats and oils, discretionary foods) based on an eight-digit code assigned to each food item. For recipes comprising items from several food groups, an appropriate code was manually assigned. For example, a spaghetti bolognaise recipe comprising pasta, mince, vegetables and cheese (i.e. grains, meat, vegetables and dairy) was assigned a code different from that of a chicken chow mein recipe comprising rice, chicken, vegetables and oil (grains, meat, vegetables and fats and oils). Coding decisions were discussed between two study investigators. Food group provision and consumption in grams was converted to servings based on the Australian Guide to Healthy Eating ${ }^{(10)}$.

\section{Intervention fidelity}

Nutrition policy, menu and eating environment data were collected at baseline (by researchers) and follow-up (by SRER dietitians as part of the SRER award process) using the SRER award criteria checklist. This checklist comprises five sections: (i) SRER training status audit (one item); (ii) direct observation of the centre eating environment (ten items); (iii) nutrition policy audit (twenty-six items); (iv) menu assessment (twenty-five items); and (v) food safety record audit (two items). The checklist was developed by SRER to evaluate centres against the award criteria ${ }^{(4,5)}$. Each item is scored yes $(=1) /$ no $(=0)$ and summed for a maximum score of 64 . Example checklist items include: cook and director trained in SRER (training criteria); staff supervise children while eating and interact calmly and positively, menu and recipes available to parents (eating environment criteria); reference to choking prevention, healthy fundraising, relevant dietary guidelines (policy criteria); food safety programme and staff training log (food safety criteria). A full list of item details is available from the authors. The menu assessment was based on an invoice-based menu assessment tool which has been validated for use in LDCC $^{(8)}$. At baseline and follow-up centres provided detailed information on the previous fortnight's menu including corresponding receipts and details of any donated foods. Estimated servings of grains, fruit, vegetables, dairy, meat and alternatives, and fats and oils provided per child per day were compared against recommended food group targets that would provide $50 \%$ of children's Nutrient Reference Values (NRV) ${ }^{(11)}$.

\section{Data analysis}

Analyses were conducted in SPSS Statistics version 17.0. The level of significance was set at $P<0.05$.

\section{Child outcomes}

Food group intake data (in servings/d) were not normally distributed, so median and interquartile ranges (IQR) are reported. Food group servings (provided and consumed) at baseline and follow-up were compared using the MannWhitney $U$ test. Nutrient intakes (provided and consumed) were normally distributed, so mean and standard deviation are reported. As children's dietary intake was assessed crosssectionally (i.e. not all the same children at baseline and follow-up), comparisons pre and post were made using the independent-samples $t$ test. Average energy and nutrient intakes were compared with the value equivalent to $50 \%$ of the appropriate NRV for Australia and New Zealand ${ }^{(11)}$.

\section{Centre outcomes}

Centre compliance was determined by adding all items within each section of the site visit checklist (yes $=1$, no $=0$ ). Where there were missing values, compliance was calculated from all available data (e.g. 23/24) and scaled up to a value representing all items (e.g. 24/25). Total compliance was calculated as the sum of all sections. Average compliance at baseline and follow-up was compared using paired $t$ tests. Average food group servings provided per child per day according to the two-week menu analysis were predominantly normally distributed and compared at baseline and follow-up using paired $t$ tests. However, for ease of comparison with the childlevel data, median and interquartile ranges are reported.

\section{Results}

\section{Sample characteristics}

All twenty eligible centres participated in the study. Centres had an average total daily attendance of fifty-nine children, ranging in age from 6 months to 5 years. Children without complete dietary data (i.e. morning tea, lunch and afternoon tea) were excluded ( $n 23$ at baseline, $n 19$ at follow-up). Analysis was conducted on data from 216 children aged 2-4 years at baseline and 221 at follow-up. Only $14 \%$ of children contributed data at both data collection points. Children were, on average, aged 2.5 years (baseline, 2.5 (SD 0.4) years; follow-up, 2.5 ( $\mathrm{SD} 0.3$ ) years) and the majority were boys (baseline 62\%; follow-up 55\%).

\section{Intervention fidelity}

At baseline, centres had considerable potential to improve the eating environment, menu and nutrition policy as assessed against the SRER criteria checklist (Table 1). The average compliance with the SRER criteria checklist was $36 \cdot 6$ (SD 2.7) out of a possible score of 64 , which increased significantly to $62.4(\mathrm{SD} 4 \cdot 2)$ out of 64 after participation in 
Table 1 Compliance with Start Right - Eat Right (SRER) site visit checklist criteria at baseline and follow-up* among twenty long day care centres in metropolitan Adelaide, South Australia, Australia, 2012

\begin{tabular}{|c|c|c|c|c|}
\hline \multirow[b]{3}{*}{ Criteria section and item } & \multicolumn{4}{|c|}{ Criteria met } \\
\hline & \multicolumn{2}{|c|}{ Baseline } & \multicolumn{2}{|c|}{ Follow-up } \\
\hline & $n$ & $\%$ & $n$ & $\%$ \\
\hline \multicolumn{5}{|l|}{ Training criteria } \\
\hline Director/cook undertaken SRER training previous 4 years & 0 & 0 & 19 & 95 \\
\hline \multicolumn{5}{|l|}{ Eating environment criteria } \\
\hline Staff eat same food as children & 2 & 10 & $19 \dagger$ & 95 \\
\hline Eating is supervised & $1 \overline{5}$ & 75 & $19+$ & 95 \\
\hline Foods served are discussed with children & 7 & 35 & $19 \dagger$ & 95 \\
\hline Relaxed (non-pressure) eating environment & 15 & 75 & $19+$ & 95 \\
\hline Food awareness activities are offered in the centre programme & 17 & 85 & $19 \dagger$ & 95 \\
\hline Parent nutrition education offered quarterly in the centre programme & 12 & 60 & $19 \dagger$ & 95 \\
\hline Menu recipes available to parents & 16 & 80 & $19 \dagger$ & 95 \\
\hline \multicolumn{5}{|l|}{ Policy criteria } \\
\hline Lists choking prevention precautions & 0 & 0 & 20 & 100 \\
\hline Describes methods for staff food communication with parents & 0 & 0 & 20 & 100 \\
\hline States examples of healthy fundraising activities & 0 & 0 & 20 & 100 \\
\hline Describes children's food/nutrition awareness activities & 0 & 0 & 20 & 100 \\
\hline States supports breast milk provision and breast-feeding mothers & 0 & 0 & 20 & 100 \\
\hline Lists recommended stages for introducing solids & 0 & 0 & 20 & 100 \\
\hline Lists fluids appropriate from birth to age 5 years & 0 & 0 & 20 & 100 \\
\hline Lists special dietary needs procedure & 0 & 0 & 20 & 100 \\
\hline \multicolumn{5}{|l|}{ Menu criteria } \\
\hline Menu planned fortnightly in advance & 18 & 90 & 20 & 100 \\
\hline Morning and afternoon snacks included in the menu & 18 & 90 & 20 & 100 \\
\hline Second (late) afternoon snack offered ${ }^{*}$ & 13 & 65 & 19 & 95 \\
\hline Menu culturally inclusive & 15 & 75 & 20 & 100 \\
\hline Food/drink provision consistent with dietary guidelines & 12 & 60 & 20 & 100 \\
\hline Lean red meat on menu four times/fortnight & $0 \ddagger$ & 0 & 19 & 95 \\
\hline Lean white meat on menu three times/fortnight & $14 \ddagger$ & 70 & 19 & 95 \\
\hline Vegetarian option on menu two times/fortnight & $3 \ddagger$ & 15 & 19 & 95 \\
\hline Vegetarian/white meat options served with iron-containing food & $0 \ddagger$ & 0 & 18 & 90 \\
\hline Vitamin C-rich fruit or vegetables served with vegetarian options & $5 \ddagger$ & 25 & 19 & 95 \\
\hline High-fat meals/snacks limited to two times/fortnight & $5 \ddagger$ & 25 & 18 & 90 \\
\hline Vegetables on menu daily & $11 \neq$ & 55 & 19 & 95 \\
\hline Grain foods on menu twice daily & $1 \ddagger$ & 5 & 19 & 95 \\
\hline High-fibre grain foods offered four times/fortnight & $8 \ddagger$ & 40 & 19 & 95 \\
\hline Only lean meats are used & 17 & 85 & 17 & 85 \\
\hline Poly- or monounsaturated oil/margarine used & 11 & 55 & 20 & 100 \\
\hline \multicolumn{5}{|l|}{ Food safety criteria } \\
\hline Food safety programme audit report & $15 \dagger$ & 75 & 18 & 90 \\
\hline Staff food hygiene training log & $16 \dagger$ & 80 & 18 & 90 \\
\hline \multicolumn{5}{|l|}{ Total assessment } \\
\hline Average compliance (out of 64 ) & $36 \ddagger$ & 56 & $63+$ & 98 \\
\hline
\end{tabular}

${ }^{*}$ Criteria items met by all centres at baseline (i.e. no room for improvement) not listed (full list of item details available from the authors). †Missing: $n 1$.

¥Missing: $n 2$ (menu not provided).

the SRER programme $(P<0 \cdot 001)$. At follow-up, $80 \%$ of centres were fully compliant with the SRER award criteria (Table 2).

At baseline, the number of centres meeting the target number of servings per child per day based on the twoweek, centre-level, invoice-based menu assessment tool was lowest for meat and alternatives (22\% of centres), dairy ( $50 \%$ of centres) and vegetables ( $50 \%$ of centres). At least $90 \%$ of centres met the targets for all food groups following implementation of SRER. Available food group servings per child per day based on the menu assessment tool at baseline and follow-up are shown in Table 3. According to the twoweek menu audit, the median daily servings of vegetables (1.0 (IQR 0.6-1.2) v. 1.4 (IQR 1.1-1.8), P<0.001) and meat and alternatives $(0 \cdot 8$ (IQR $0 \cdot 6-0 \cdot 9)$ v. $1 \cdot 1$ (IQR 1.0-1.3), $P=0.001)$ available to children improved significantly following the implementation of the programme.

\section{Children's dietary intake}

Foods

Servings of food provided to and consumed by children as assessed via the plate wastage method are shown in Table 3. Provision of core food groups increased significantly (all $P<0.001$ ), ranging from an increase of $0 \cdot 1-0 \cdot 2$ servings/d for vegetables, dairy and meat and alternatives to $0.4-0.5$ servings/d for grains and fruit. Increases of a similar magnitude were observed in the 
Table 2 Compliance with Start Right - Eat Right criteria checklist at baseline and follow-up among twenty long day care centres in metropolitan Adelaide, South Australia, Australia, 2012

\begin{tabular}{|c|c|c|c|c|c|c|c|c|c|c|}
\hline & \multirow[b]{3}{*}{ Max. score } & \multicolumn{4}{|c|}{ Meeting all criteria maximum score } & \multicolumn{4}{|c|}{ Criteria compliance $^{*}$} & \multirow[b]{3}{*}{$P$ value } \\
\hline & & \multicolumn{2}{|c|}{ Baseline } & \multicolumn{2}{|c|}{ Follow-up } & \multicolumn{2}{|c|}{ Baseline } & \multicolumn{2}{|c|}{ Follow-up } & \\
\hline & & $n$ & $\%$ & $n$ & $\%$ & Mean & SD & Mean & SD & \\
\hline Training criteria & 1 & 0 & 0 & 18 & 90 & 0.0 & 0.0 & 0.9 & 0.3 & $\mathrm{~N} / \mathrm{A}$ \\
\hline Eating environment criteria & 10 & 1 & 5 & $19 \S$ & 95 & $7 \cdot 2$ & 1.4 & $9.5 \|$ & $2 \cdot 2$ & 0.001 \\
\hline Policy criteria & 26 & 0 & 0 & 20 & 100 & $13 \cdot 0$ & 0.0 & $26 \cdot 0$ & 0.0 & $\mathrm{~N} / \mathrm{A}$ \\
\hline Menu criteria & 25 & 0 & 0 & 15 & 75 & $14 \cdot 9 \|$ & 1.9 & $24 \cdot 2$ & $2 \cdot 5$ & $<0.001$ \\
\hline Food safety criteria & 2 & 12 & 60 & 17 & 85 & 1.6 & 0.6 & $1 \cdot 8$ & 0.5 & 0.096 \\
\hline Total checklist score & 64 & 0 & 0 & 16 & 80 & $36 \cdot 6$ & $2 \cdot 7$ & $62 \cdot 4$ & $4 \cdot 2$ & $<0.001$ \\
\hline
\end{tabular}

${ }^{*}$ Criteria compliance was calculated by summing together the number of criteria items achieved (yes $=1 /$ no $=0$ ) for checklist sections and total.

†Number of items per checklist criteria section.

$\ddagger$ Paired $t$ test used to compare mean compliance at baseline and follow-up. N/A indicates $t$ test cannot be computed because the standard error of the difference is 0 .

$\S n 19$ as eating environment criteria assessment was not completed by one centre.

IIn 18 as menu assessment tool component was not completed by two centres.

children's consumption of grains, fruit, dairy and meat and alternatives. However, while the provision of vegetables increased, the increase in consumption was not statistically significant (0.4 (IQR 0.0-0.9) servings/d at baseline; 0.5 (IQR CI $0.0-1 \cdot 0$ ) servings/d at follow-up, $P=0.083$ ). Provision and consumption of fats and oils and discretionary foods were low at baseline, and further decreases were observed at follow-up (Table 3).

\section{Nutrients}

At baseline, the average energy intake was below $50 \%$ of the estimated energy requirement range for 2- to 4-yearolds, and the total fat, carbohydrate and protein intakes fell within the acceptable macronutrient distribution ranges (Table 4). Baseline provision (6.9 (sD 3.5) g/d) and consumption (5.0 (SD 3.1) g/d) of fibre were below the benchmark of $50 \%$ of the NRV $(7 \mathrm{~g} / \mathrm{d})$. Provision and consumption of saturated fat and $\mathrm{Na}$ at baseline were in excess of the benchmark (Table 4). The average micronutrients provided and consumed were all in excess of $50 \%$ of the relevant NRV except for $\mathrm{K}$ and folate intakes (Table 4). Over half of children met the NRV benchmark for most nutrients at baseline (data not shown). However, the percentage of children meeting the benchmark for fibre, $\mathrm{Ca}$ and sodium $\mathrm{Na}$ was low at baseline (20\%, $43 \%$ and $42 \%$, respectively) and increased at follow-up (30\%, $52 \%$ and $63 \%$, respectively).

Provision and consumption of energy were higher at follow-up compared with baseline (Table 4). No change in percentage of energy from total fat was observed. Percentage of energy intake as saturated fat was lower at follow-up for consumption (13.4 (sD 5.7)\% v. 12.4 (sD 4.6 ) \%, $P=0.034)$, with a trend observed for provision (13.0 (SD 5.2) \% v.12.2 (SD 4.3) \%, $P=0.08$ ). Percentage of energy consumed as protein was higher at follow-up, with no difference observed in percentage of energy from carbohydrate (Table 4). Ca, K, Mg, P, Zn, riboflavin, niacin and folate all increased significantly post-implementation (Table 4).
Provision (but not consumption) of fibre also increased. Sugar, vitamin A, vitamin C, thiamin and Fe intakes did not change. Provision and consumption of $\mathrm{Na}$ decreased significantly following the intervention (Table 4).

\section{Discussion}

The current pre-post intervention study aimed to evaluate the outcome of a long day care nutrition award scheme on the food and nutrient intakes of young children. Intervention fidelity measures showed that, at follow-up, $80 \%$ of centres complied with all scheme criteria for award status. Centre provision and children's consumption of grains, fruit, dairy and meat and alternatives increased. Vegetable provision increased, but a significant increase in children's consumption was not achieved. Between baseline and follow-up, children's intakes of energy and most micronutrients increased, while intakes of saturated fat and $\mathrm{Na}$ decreased. Consumption of fibre, sugar, vitamin $\mathrm{A}$, vitamin $\mathrm{C}$, thiamin and $\mathrm{Fe}$ did not change, nor did percentage of energy from total fat or carbohydrate. The study findings indicate that implementation of a long day care nutrition award scheme does translate into improvements in children's dietary intake while they are in care.

Improvements were observed in centres' policies, menus and eating environments, verifying that the SRER scheme was implemented as intended. Other studies have evaluated SRER $^{(4-6)}$ and similar interventions that also utilise a staff training and self-assessment process to promote nutrition policy, menus and practices that are consistent with recommendations ${ }^{(12)}$. The doubling in score to achieve full compliance with the policy criteria is consistent with a previous evaluation of the SRER scheme ${ }^{(4)}$. In a recent US randomised controlled trial, a fivefold increase in policy score was observed following a 7-month Nutrition and Physical Activity Self-Assessment for Child Care (NAP SACC) 
intervention $^{(13)}$. However, following implementation of NAP SACC, mean policy criteria scores remained low at 5.2 (range: 0-11) out of a possible score of 20. This is consistent with other randomised and quasi-experimental studies evaluating NAP SACC in the USA ${ }^{(14-16)}$. One possible reason for better results in the present study is that SRER is implemented by dietitians, while the NAP SACC intervention is delivered by nurse child-care health consultants. Programmes such as SRER and NAP SACC that work in partnership with staff to optimise child care nutrition policy, menus and practices are feasible, achievable and have good reach. While impact evaluation results are encouraging, these programmes may not automatically translate into changes in children's dietary intake or health status. This highlights the need to include measures of outcome evaluation to fully understand their effectiveness.

Child-care centres being an important setting for nutrition promotion has been highlighted in a number of crosssectional studies. They show that children are not being provided with or consuming the recommended servings of nutritious foods compared with national guidelines ${ }^{(7,17-19)}$. In the present study, median baseline daily food group servings estimated using an invoice-based menu assessment tool were at or above recommendations apart from meat and alternatives. However, $22-50 \%$ of the individual centres were not meeting the food group servings targets for meat and alternatives, dairy foods and vegetables. At the child level, baseline food provision and consumption assessed using the weighed plate wastage method showed median daily servings below recommendations for all food groups except fruit. Consistent with previous studies $^{(18,20,21)}$, provision of grains, dairy foods and meat and alternatives was only $25-45 \%$ of food group servings recommendations. While provision of vegetables and fruit was close to recommendations, children's consumption was only $40-60 \%$ of the target servings. With over $60 \%$ of children in developed countries spending on average $18-30 \mathrm{~h} /$ week in formal child care ${ }^{(13,22)}$, nutrition promotion activities to improve food provision and consumption of nutritious foods while in child care remain important.

At follow-up, $90 \%$ of the study centres met all of the food group servings recommendations, with significant improvements in servings of vegetables $(\sim 0.4$ servings/d) and meat and alternatives ( $\sim 0.2$ servings/d) using the invoice-based menu assessment tool. Significant increases were also observed in foods provided to and consumed by children assessed via the plate wastage method. The magnitude of the change in food provided was consistent with the change in servings consumed. The changes were largest for grains and fruit $(\sim 0.5$ servings/d), with only small increases for dairy and meat and alternatives $(\sim 0 \cdot 2$ servings/d). While a small increase in the provision of vegetables $(\sim 0 \cdot 1$ servings/d) was observed, this was not significant for food consumption. Inclusion of fats and oils, or discretionary foods was not prominent in centres 
Table 4 Daily energy and nutrient provision and consumption at baseline ( $n 216)$ and follow-up $(n 221)^{\star}$ by 2- to 4-year-old children attending twenty long day care centres implementing the Start Right - Eat Right nutrition award scheme, metropolitan Adelaide, South Australia, Australia, 2012

\begin{tabular}{|c|c|c|c|c|c|c|c|c|c|c|c|}
\hline & \multirow[b]{3}{*}{ Benchmark $50 \% \mathrm{NRV}^{*}$} & \multicolumn{4}{|c|}{ Provided } & \multirow[b]{3}{*}{$P$ value $\dagger$} & \multicolumn{4}{|c|}{ Consumed } & \multirow[b]{3}{*}{$P$ value $\dagger$} \\
\hline & & \multicolumn{2}{|c|}{ Baseline } & \multicolumn{2}{|c|}{ Follow-up } & & \multicolumn{2}{|c|}{ Baseline } & \multicolumn{2}{|c|}{ Follow-up } & \\
\hline & & Mean & SD & Mean & SD & & Mean & SD & Mean & SD & \\
\hline Energy (kJ) & 2450 & $2137 \cdot 0$ & $714 \cdot 1$ & 2344.3 & 773.6 & 0.004 & $1629 \cdot 7$ & 742.7 & $1790 \cdot 6$ & $820 \cdot 4$ & 0.032 \\
\hline Fat $(\mathrm{g})$ & - & 16.5 & 8.8 & 17.0 & $7 \cdot 2$ & 0.489 & 12.9 & 8.0 & 13.2 & $7 \cdot 1$ & 0.666 \\
\hline Fat ( $\%$ of energy) & 20-35 & $27 \cdot 6$ & 8.3 & $26 \cdot 8$ & $6 \cdot 7$ & 0.272 & 28.5 & 9.5 & $27 \cdot 4$ & $7 \cdot 1$ & 0.176 \\
\hline Saturated fat $(\mathrm{g})$ & - & 7.8 & 4.8 & $7 \cdot 7$ & 3.8 & 0.904 & $6 \cdot 1$ & $4 \cdot 2$ & $6 \cdot 0$ & 3.6 & 0.747 \\
\hline Saturated fat (\% of energy) & 10 & 13.0 & $5 \cdot 2$ & $12 \cdot 2$ & 4.3 & 0.088 & $13 \cdot 4$ & $5 \cdot \overline{7}$ & $12 \cdot 4$ & 4.6 & 0.034 \\
\hline Protein $(\mathrm{g})$ & 6 & $22 \cdot 2$ & 9.4 & $25 \cdot 3$ & 10.9 & 0.002 & $16 \cdot 8$ & $9 \cdot 1$ & $19 \cdot 6$ & $10 \cdot 9$ & 0.003 \\
\hline Protein (\% of energy) & 15 & $17 \cdot 6$ & 3.9 & $18 \cdot 1$ & 3.7 & 0.198 & $17 \cdot 3$ & $4 \cdot 1$ & $18 \cdot 1$ & $4 \cdot 0$ & 0.042 \\
\hline Carbohydrate $(\mathrm{g})$ & - & $64 \cdot 3$ & 23.3 & 73.2 & $25 \cdot 2$ & 0.000 & 48.7 & 23.9 & 55.2 & $25 \cdot 7$ & 0.006 \\
\hline Carbohydrate (\% of energy) & $45-65$ & $50 \cdot 4$ & $11 \cdot 2$ & $51 \cdot 0$ & 97.8 & 0.519 & $50 \cdot 1$ & $12 \cdot 2$ & $50 \cdot 7$ & $8 \cdot 1$ & 0.557 \\
\hline Sugars $(\mathrm{g})$ & - & $26 \cdot 8$ & $11 . \overline{6}$ & 28.9 & 13.7 & 0.087 & $20 \cdot 2$ & $12 \cdot 1$ & $21 \cdot 2$ & $13 \cdot 1$ & 0.395 \\
\hline Dietary fibre (g) & 7 & $6 \cdot 8$ & 3.0 & 7.5 & 2.8 & 0.012 & $5 \cdot 0$ & 3.0 & 5.4 & $2 \cdot 8$ & 0.108 \\
\hline $\mathrm{Ca}(\mathrm{mg})$ & 180 & 257.5 & $142 \cdot 1$ & $302 \cdot 8$ & 141.4 & 0.001 & $198 \cdot 4$ & $126 \cdot 0$ & 233.2 & $135 \cdot 0$ & 0.006 \\
\hline $\mathrm{Fe}(\mathrm{mg})$ & 2 & 2.7 & 1.1 & $2 \cdot 7$ & $1 \cdot 1$ & 0.551 & $2 \cdot 0$ & 1.1 & $2 \cdot 1$ & 1.2 & 0.523 \\
\hline $\mathrm{Na}(\mathrm{mg})$ & 500 & 871.6 & $613 \cdot 4$ & 648.8 & $457 \cdot 6$ & 0.000 & 675.0 & 532.5 & 491.5 & 365.7 & 0.000 \\
\hline $\mathrm{K}(\mathrm{mg})$ & 1000 & 720.9 & 237.8 & 858.5 & $304 \cdot 3$ & 0.000 & 534.7 & $262 \cdot 3$ & $642 \cdot 8$ & $315 \cdot 7$ & 0.000 \\
\hline $\operatorname{Mg}(\mathrm{mg})$ & $32 \cdot 5$ & 70.5 & $22 \cdot 1$ & 83.6 & 28.5 & 0.000 & 52.9 & 23.4 & 63.5 & 28.8 & 0.000 \\
\hline$P(\mathrm{mg})$ & 190 & 403.8 & 145.5 & 455.4 & $170 \cdot 6$ & 0.001 & 310.5 & $149 \cdot 6$ & 351.4 & $172 \cdot 3$ & 0.008 \\
\hline $\mathrm{Zn}(\mathrm{mg})$ & 1.25 & 2.9 & 1.5 & 3.5 & 1.8 & 0.000 & 2.2 & 1.4 & 2.7 & 1.8 & 0.001 \\
\hline Vitamin A $(\mu \mathrm{g})$ & 155 & 286.7 & $172 \cdot 3$ & 286.0 & $135 \cdot 7$ & 0.961 & 209.4 & $163 \cdot 1$ & 203.4 & $122 \cdot 7$ & 0.665 \\
\hline Vitamin C (mg) & 12.5 & 24.7 & 15.5 & 26.9 & $21 \cdot 1$ & 0.208 & $15 \cdot 9$ & 13.5 & 18.7 & 17.6 & 0.065 \\
\hline Thiamin (mg) & 0.2 & 0.5 & 0.4 & 0.5 & 0.6 & 0.426 & 0.4 & 0.3 & 0.4 & 0.5 & 0.324 \\
\hline Riboflavin (mg) & 0.2 & 0.6 & 0.4 & 0.7 & 0.6 & 0.000 & 0.4 & 0.4 & 0.6 & 0.5 & 0.000 \\
\hline $\operatorname{Niacin}(\mathrm{mg})$ & 2.5 & $10 \cdot 0$ & $4 \cdot 3$ & 13.1 & 6.3 & 0.000 & 7.5 & 3.9 & $10 \cdot 2$ & 5.9 & 0.000 \\
\hline Folate $(\mu \mathrm{g})$ & 75 & 81.5 & $46 \cdot 3$ & $146 \cdot 1$ & $141 \cdot 1$ & 0.000 & $60 \cdot 2$ & $36 \cdot 5$ & 110.4 & $116 \cdot 9$ & 0.000 \\
\hline
\end{tabular}

${ }^{*} \mathrm{NRV}$, Nutrient Reference Value ${ }^{(11)}$. Estimated Average Requirement (EAR) or Adequate Intake (AI) where an EAR is not available. Upper Level of Intake (UL) for $\mathrm{Na}$. Acceptable Macronutrient Distribution Ranges (AMDR) for macronutrient expressed as a percentage of total energy intake.

†Data were compared using independent-samples $t$ test.

evaluated. This is not surprising as secondary analysis of Australian dietary intake data indicates that while 2- to 3 -year-old children's intake of discretionary foods is excessive $^{(23)}, 75 \%$ of discretionary foods are consumed at home with only $7 \%$ consumed within institutions such as child-care centres ${ }^{(24)}$. Overall, optimising the nutrition policy and menus in child care does achieve a centre-level food supply that is consistent with recommendations. While this does translate into changes in provision and consumption at the child level, there remains scope to refine provision of grains, dairy and meat and alternatives. The introduction of strategies that encourage consumption, particularly for vegetables, may also be warranted.

Previous intervention studies have assessed children's intake while in child care, but only for selected foods. A recent study showed a 0.3 serving/d increase in vegetable content of menus analysed before and after adoption of new child-care nutrition policies (one centre, thirty menus), but actual consumption was not assessed ${ }^{(25)}$. In the randomised controlled trial evaluating the NAP SACC intervention, there was an $8 \%$ increase in the provision of healthy foods and a $10-17 \%$ increase in centre nutrition practices (e.g. use of low-fat milk, low-fat meat or legumes) assessed using a validated direct observation checklist ${ }^{(13)}$. While these changes were not statistically significant, the NAP SACC intervention was associated with a $-0.14(95 \% \mathrm{CI}-0.26,-0.02, P=0.002)$ difference in BMI $Z$-score compared with a control group ${ }^{(13)}$. Increases in fruit and vegetable intake of 0.1 to 0.3 servings/d have also been observed in response to child-care curricula $^{(26,27)}$ and lunchbox ${ }^{(28)}$ interventions. Child-care interventions to date, including SRER, achieve small but meaningful improvements in children's food intake. Further programme enhancements are required, with some examples relating to the promotion of vegetable consumption discussed below.

SRER menu criteria aim to ensure that the food provided meets $50 \%$ of the relevant $\mathrm{NRV}^{(4,5)}$. At baseline the estimated mean macro- and micronutrient contents of foods provided were all in excess of these criteria, apart from $\mathrm{K}$, folate and fibre. Of particular note is that saturated fat and $\mathrm{Na}$ levels exceeded NRV levels and mean energy intake was $\sim 80 \%$ of the age-specific NRV. At follow-up, improvements in children's nutrient intake were observed for energy and eleven of the nineteen nutrients evaluated. While the increase in energy and nutrient intakes reflects an increase in food provision, the increase in fibre and decreases in $\mathrm{Na}$ and saturated fat indicate that the scheme did improve the quality of the food provided. Energy, saturated fat and $\mathrm{Na}$ intakes remained inconsistent with 
recommendations and highlight areas for refinement of SRER criteria.

To our knowledge, these results are the first published changes in the provision and consumption of energy and nutrients by children while in child care following implementation of a nutrition policy, menu and eating environment intervention. However, the results are consistent with changes in energy and nutrient intakes following the introduction of food-based standards in UK primary schools $^{(29)}$. One could hypothesise that an increase in energy intake may not necessarily place children at increased risk of excess weight gain. Young children are able to self-regulate energy intake to need ${ }^{(30)}$. A higher energy intake derived from nutritious foods while in child care could displace intake of poorer food choices at home. Exploring this hypothesis is required in further research that measures dietary intake over the whole day. The impact of an increase in energy intake on health outcomes such as adiposity and cardiovascular risk factors such as blood pressure should also be evaluated.

Baseline provision of vegetables and fruit was closest to the recommended targets ( $70-120 \%$, respectively), but only $50 \%$ of vegetable and fruit servings were consumed. Further, at follow-up vegetable intake was not higher and vegetable waste had increased. Optimising food provision is one of the steps needed to increase children's fruit and, particularly, vegetable consumption. However, additional factors such as familiarity and repeated exposure influence children's consumption, both at home and while in child care $^{(19)}$. Strategies such as repeated exposure ${ }^{(31)}$, peer role modelling $^{(32,33)}$ or serving vegetables before the main course ${ }^{(34)}$ may be needed in addition to increased provision to increase children's intake. While some of these strategies are covered in the centre director and cook training, training enhancements that also include digital video disk or online training for floor staff supervising mealtimes many be beneficial. Child-care staff should be reassured that children are capable of increasing fruit and vegetable intake if given them regularly and often enough.

The study is not without limitations. The pre-post design does not adequately control for potential bias and study findings need to be replicated utilising a controlled design. However, the inclusion of measures of intervention fidelity does provide some confidence, in the absence of a comparison group, that the improvements in children's dietary intakes were secondary to SRER participation. The 6-month period between baseline and follow-up and resource limitations that confined dietary assessed to a single day meant that it was not logistically possible to follow up the same children due to parttime attendance and movement into the kindergarten room. However, this is offset by the robust collection of dietary intake data by trained professionals and the large sample size, which meant that the study had sufficient power to detect changes in food and nutrient intakes. The single day's assessment of children's dietary intake is acceptable for evaluating differences at the group level ${ }^{(35)}$. Follow-up was confined to immediately post-intervention. Longer-term follow-up is required to determine whether children's intake changes further once acclimatised to the new menus and whether change is maintained in the long term.

LDCC, often providing over half of children's daily food intake, are excellent avenues for nutrition promotion to support young children's growth and development. The study findings indicate that implementation of a long day care nutrition award scheme that optimises the menus, eating environment and nutrition policy of centres does translate into improvements in energy, food and nutrient intakes of 2- to 4-year-olds while in care. Future studies that include a comparison group, long-term follow-up and consider changes in dietary intake while in care in the context of total daily intake are required to verify these findings. Future research could also explore changes in food intake achieved through inclusion of nutrition strategies to reduce food waste, particularly with regard to vegetables, to maximise the impact and cost effectiveness of food-service interventions.

\section{Acknowledgements}

Acknowledgements: The authors thank Goodstart for their support of the research undertaken; all child-care staff who participated in the project; and Ms C. Grant and Ms U. George for their role in data collection. Financial support: The study was funded by a University of South Australia Development grant. SA Health funded SRER, which was managed through Southern Adelaide Health Service in partnership with Gowrie, South Australia. R.K.G. is supported by a National Heart Foundation Fellowship (PH11A6058). The funders had no role in the design, analysis or writing of this article. Conflict of interest: J.H. was Project Manager of the SRER SA programme. All other authors have no conflicts of interest to declare. Authorship: R.K.G. designed this study. L.B. was involved in data collection. L.B. and G.H. analysed the data. All authors were involved in data interpretation and manuscript development. Ethics of human subject participation: Ethics approval was granted by University of South Australia Human Research Ethics Committee (UniSA HREC \#26875).

\section{References}

1. Lawlis TR, Mikhailovich K \& Morrison P (2006) Healthy Eating Programs, Resources and Staff Training in Long Day Care Settings. Canberra: University of Canberra.

2. Kaphingst KM \& Story M (2009) Child care as an untapped setting for obesity prevention: state child care licensing regulations related to nutrition, physical activity, and media use for preschool-aged children in the United States. Prev Chronic Dis 6, A11. 
3. Pollard C \& Lewis J (1999) Food service in long day care centres - an opportunity for public health intervention. Aust N Z J Public Health 23, 606-610.

4. Matwiejczyk L, McWhinnie JA \& Colmer K (2007) An evaluation of a nutrition intervention at childcare centres in South Australia. Health Promot J Aust 18, 159-162.

5. Pollard C, Lewis J \& Miller M (2001) Start Right-Eat Right award scheme: implementing food and nutrition policy in child care centers. Health Educ Behav 28, 320-330.

6. Golley RK, Bell LK, Matwiejczyk L et al. (2012) South Australian long day care centres engaged with a nutrition incentive award scheme show consistency with mealtime practice guidelines. Nutr Diet 69, 130-136.

7. Larson N, Ward DS, Neelon SB et al. (2011) What role can child-care settings play in obesity prevention? A review of the evidence and call for research efforts. J Am Diet Assoc 111, 1343-1362.

8. Pollard C, Lewis J, Barkess J et al. (2002) The development and preliminary testing of an invoice based menu assessment tool for long day child care centres. Nutr Diet 59, 195-200.

9. Food Standards Australia New Zealand (2008) AUSNUT 2007 - Australian Food, Supplement and Nutrient Database for Estimation of Population Nutrient Intakes. http://www. foodstandards.gov.au/consumerinformation/ausnut2007/ (accessed November 2010).

10. National Health and Medical Council (2013) Australian Guide to Healthy Eating. Canberra: Commonwealth Government of Australia.

11. National Health and Medical Research Council (2006) Nutrient Reference Values for Australia and New Zealand. Canberra: Commonwealth Government of Australia; available at http://www.nrv.gov.au/

12. Ammerman AS, Ward DS, Benjamin SE et al. (2007) An intervention to promote healthy weight: Nutrition and Physical Activity Self-Assessment for Child Care (NAP SACC) theory and design. Prev Chronic Dis $\mathbf{4}$, A67.

13. Alkon A, Crowley AA, Neelon SE et al. (2014) Nutrition and physical activity randomized control trial in child care centers improves knowledge, policies, and children's body mass index. BMC Public Health 14, 215.

14. Alkon A, Bernzweig J, To K et al. (2009) Child care health consultation improves health and safety policies and practices. Acad Pediatr 9, 366-370.

15. Crowley AA \& Kulikowich JM (2009) Impact of training on child care health consultant knowledge and practice. Pediatr Nurs 35, 93-100.

16. Hanna H, Mathews R, Southward LH et al. (2012) Use of paid child care health care consultants in early care and education settings: results of a national study comparing provision of health screening services among Head Start and non-Head Start centers. J Pediatr Health Care 26, 427-435.

17. Briley ME, Jastrow S, Vickers J et al. (1999) Dietary intake at childcare centers and away: are parents and care providers working as partners or at cross-purposes? J Am Diet Assoc 99, 950-954.

18. Erinosho T, Dixon LB, Young C et al. (2011) Nutrition practices and children's dietary intakes at 40 child-care centers in New York City. J Am Diet Assoc 111, 1391-1397.
19. Gubbels JS, Kremers SP, Stafleu A et al. (2010) Child-care environment and dietary intake of 2- and 3-year-old children. J Hum Nutr Diet 23, 97-101.

20. Ball SC, Benjamin SE \& Ward DS (2008) Dietary intakes in North Carolina child-care centers: are children meeting current recommendations? J Am Diet Assoc 108, 718-721.

21. Padget A \& Briley ME (2005) Dietary intakes at child-care centers in central Texas fail to meet Food Guide Pyramid recommendations. J Am Diet Assoc 105, 790-793.

22. Houng B, Jeon SE \& Kalb G (2011) The Effects of Childcare on Child Development. Melbourne: Melbourne Institute of Applied Economic and Social Research.

23. Golley RK \& Hendrie GA (2014) The Dietary Guideline Index for Children and Adolescents: what is the impact of the new dietary guidelines? Nutr Diet 71, 210-212.

24. Commonwealth Scientific Industrial Research Organisation \& University of South Australia (2008) 2007 Australian National Children's Nutrition and Physical Activity Survey - Main Findings. Canberra: Commonwealth Government, Department of Health and Ageing.

25. Turner-McGrievy GM, Hales SB \& Baum AC (2014) Transitioning to new child-care nutrition policies: nutrient content of preschool menus differs by presence of vegetarian main entree. J Acad Nutr Diet 114, 117-123.

26. De Bock F, Breitenstein L \& Fischer JE (2012) Positive impact of a pre-school-based nutritional intervention on children's fruit and vegetable intake: results of a clusterrandomized trial. Public Health Nutr 15, 466-475.

27. Witt KE \& Dunn C (2012) Increasing fruit and vegetable consumption among preschoolers: evaluation of Color Me Healthy. J Nutr Educ Behav 44, 107-113.

28. Zask A, Adams JK, Brooks LO et al. (2012) Tooty Fruity Vegie: an obesity prevention intervention evaluation in Australian preschools. Health Promot J Aust 23, 10-15.

29. Golley R, Pearce J \& Nelson M (2011) Children's lunchtime food choices following the introduction of foodbased standards for school meals: observations from six primary schools in Sheffield. Public Health Nutr 14, 271-278.

30. Mallan KM, Nambiar S, Magarey AM et al. (2014) Satiety responsiveness in toddlerhood predicts energy intake and weight status at four years of age. Appetite 74, 79-85.

31. Hausner H, Olsen A \& Moller P (2012) Mere exposure and flavour-flavour learning increase 2-3 year-old children's acceptance of a novel vegetable. Appetite 58, 1152-1159.

32. Hendy HM (2002) Effectiveness of trained peer models to encourage food acceptance in preschool children. Appetite 39, 217-225.

33. Horne PJ, Greenhalgh J, Erjavec M et al. (2011) Increasing pre-school children's consumption of fruit and vegetables. A modelling and rewards intervention. Appetite 56, 375-385.

34. Spill MK, Birch LL, Roe LS et al. (2010) Eating vegetables first: the use of portion size to increase vegetable intake in preschool children. Am J Clin Nutr 91, 1237-1243.

35. Lanigan JA, Wells JC, Lawson MS et al. (2004) Number of days needed to assess energy and nutrient intake in infants and young children between 6 months and 2 years of age. Eur J Clin Nutr 58, 745-750. 